\title{
Memórias de infância e juventude de migrantes de retorno de Sáo Paulo a Pernambuco
}

\section{Memories of childhood and youth among return migrants from Sáo Paulo to Pernambuco}

Sandra Roberta Alves Silva

Mestre em Ciências Sociais pela UFCG (Universidade Federal de Campina Grande - PB) e professora do Cesac (Centro de Ensino Superior de Santa Cruz do Capibaribe - PE) sandra_roberta@yahoo.com.br

Marilda Aparecidd de Menezes

Pós-doutora em Sociologia, professora da Unidade Acadêmica de Ciências Sociais e do Programa de Pós-graduação em Sociologia (UFCG/PB) e pesquisadora do CNPq menezesmarilda@gmail.com

\section{Resumo:}

O presente artigo busca compreender as memórias sobre a infância, juventude, experiência de migraçáo, de migrantes do distrito de Páo de Açúcar, localizado no município de Taquaritinga do Norte - PE, que chegaram a São Paulo nas décadas de 1960 e 1970. Na década de 1980 houve forte "migração de retorno" decorrente das dificuldades enfrentadas na cidade de Sáo Paulo. Ao retornarem, engajaram-se na atividade de confecções de roupas. A regiâo passou a ser conhecida como "Pólo de Confecções do Agreste" devido a sua importância socioeconômica.

Palavras-chave: Jovens; Memória; Migração

\section{Abstract:}

This article seeks to understand the memories on the childhood, youth, experience of migration, migrants of the district of Pão de Açúcar, located in the municipality of Taquaritinga do Norte - PE, who migrated to São Paulo in the 1960s and 1970s. In the 1980s there was a strong "return migration" arising from the difficulties faced in the city of São Paulo. When returning engaged in the production of clothing. The region came to be known as "Polo de Confecções do Agreste" due to their socio-economic importance.

Keywords: Youth; Memory; Migration 
Já vou mãe

Mãe eu vou-me embora a hora chegou

Deixo a senhora aqui

Vou contra meu gosto

Mas eu vou

Um dia eu volto

Para lhe buscar

Vou lhe fazer um pedido

Lembrando de mim não precisa chorar

Vou partir mas lembrarei

De escrever uma cartinha pois não vou guentar

Ficar tanto tempo sem pode lhe falar

Que seja ao menos por carta

Mas com a senhora eu vou conversar... (Luiz Gonzaga)

1 - HALBWACHS, M. A Memória Coletiva. São Paulo. Editora Vértice, 2006.
2 ara tratar do tema da memória nos apoiamos em Halbwachs (2006)[1] que compreende a memória individual como sendo relacionada com os grupos e instituiçóes nas quais o indivíduo se inclui, tais como a família, a classe social, a escola, a igreja ou o trabalho. Assim, a memória "individual" sempre está relacionada à memória do grupo, nos termos definidos por Halbawachs, pelos "quadros sociais". Ainda segundo o mesmo, com relação à temporalidade, a lembrança individual não é preservada no passado, nem mantida no inconsciente de forma autônoma e inteira, mas é um trabalho de ressignificação do passado a partir do presente. O "lembrar" é um ato de reconstrução do que foi vivido no passado utilizando elementos do hoje, tais como imagens e ideias. Dessa forma, a imagem que um indivíduo tem da infância é influenciada pelo processo de mudança intelectual e perceptiva durante sua trajetória de vida.

Com o propósito de compreender as experiências vivenciadas pelos migrantes no que se refere à infância, juventude, processo migratório, trabalho, família e sociabilidades, utilizaremos fragmentos da memória.

\section{O PROCESSO MIGRATÓRIO: DÉCADAS DE 1960 A 1970}

A partir de 1930 - marco da industrializaçáo - intensificam-se as migraçôes internas, principalmente em direção a São Paulo, centro do processo de desenvolvimento econômico. Inicialmente, o Estado teve papel preponderante no agenciamento de migrantes, através da construção de estradas, concessáo de passagens, assistência na chegada, formas de acesso à terra ou emprego etc. Posteriormente, são os próprios migrantes e suas redes sociais que constituirão os mecanismos de apoio nas diversas fases do processo migratório: viagem, chegada, emprego, moradia, escola para as crianças etc.

O fluxo migratório de áreas rurais para as cidades se intensifica nas décadas de 1940 e 1950 (LOPES, 1971; 1976; SINGER, 1976) e os migrantes, mesmo que tivessem a intençáo de retornar às suas localidades de origem, tendiam a se fixar na cidade pois havia oportunidades de trabalho. Além disso, existia a possibilidade de adquirir uma profissão, ou como diria A. Garcia (1989) de se processar uma reconversão da força de trabalho para outras atividades, pois se tratava do período de formação da classe operária brasileira. Os migrantes nordestinos representavam este período na expressão eloquente como "São Paulo era bom", o que significava que, mesmo chegando a São Paulo sem uma capacitação profissional, tinham a possibilidade de mobilidade ocupacional inclusive na própria empresa. (MENEZES, 1985) 
Com a crescente esperança de ascensão profissional, devido às inúmeras oportunidades de emprego mediante o desenvolvimento industrial naquela época, havendo assim "uma possibilidade real de acumulação de recursos". (MENEZES, 2004: 120) A migração constitui-se como uma estratégia importante para as famílias camponesas, não se resumindo a regiốes mais ou menos favorecidas, onde o sujeito é apenas um ser passivo diante de um processo determinado pela estrutura social ou acumulação capitalista, mas se coloca como uma nova estratégia e oportunidade de melhorar as suas condiçóes de vida.

Ao compreender que os migrantes - homens e mulheres - são sujeitos ativos nos processos migratórios, buscamos nesse artigo através de suas narrativas analisar as trajetórias migratórias de famílias camponesas e a sua busca pela melhoria das condiçóes de vida. A partir de fragmentos da memória, homens e mulheres narram sobre suas experiências de infância, juventude, processo migratório, trabalho, família e sociabilidades.

A sra. Inácia [2] nasceu em Pão de Açúcar, sua mãe lavava roupa para particulares e seu pai era agricultor. Além de plantar e colher para subsistência, também trabalhavam para terceiros fazendo carvão e cortando madeira. Relata que seus irmãos também ajudavam na agricultura, mas a renda familiar era insuficiente e, por mais que tivesse disposição para o trabalho, não havia muita oportunidade de emprego. Vivendo uma difícil experiência e pensando em uma vida melhor para ela e toda família, aos 17 anos de idade decide ir para São Paulo.

\begin{abstract}
[...] Páo de Açúcar não tinha emprego, o emprego naquela época era agricultura, era apanhar algodão, feijão, fava, apanhar café no brejo, que a gente foi muito apanhar café no brejo né, lavava roupa de ganho, passava ferro. Não tinha emprego, os emprego era assim, era no pesado, muito sofrimento [...] Era um povo muito trabalhador né, só que os emprego era limitado, era muito pouco. Até as despesa, até a bóia de comer tinha que ser limitado, não tinha o suficiente pra você comer, pra encher a barriga, era pra comer tudo um pouquinho, que era pra dar pra todo mundo, que era muita gente e pouco alimento [...]Aí pensando numa vida melhor resolvi ir pra São Paulo, porque a vida aqui era muito dura e foi isso que me levou pra São Paulo, pra ver se melhorava de vida[...] [Inácia, 57 anos. Migrante na década de 60][3]
\end{abstract}

Diante da falta de perspectiva de vida e de sobrevivência, os jovens são obrigados a se aventurar por um mundo que, para eles, sempre foi representado pelo "o quê se ouvia dizer" do que era a vida na cidade grande. $\mathrm{Na}$ dificuldade de desenvolver a agricultura na região e o sonho de arranjar uma profissão, colocaram-se a caminho, cheios de esperança, e seguiram na incerteza rumo ao desconhecido, idealizando sonhos e contrapondo seus ideais ao que de fato viria a ser real. Realidade esta encontrada por Silva (2006) em sua dissertação, quando fala sobre migraçóes e identidades da juventude rural, relatando os sonhos e as dificuldades encontradas na cidade de origem até chegar à decisão de migrar para a zona canavieira de São Paulo:

A migração aparece-lhe sempre como uma das saídas, uma opção sempre possível de ser concretizada e, portanto, como
2 - Inácia foi pra São Paulo em 1967, retornando por volta em 1983.

3 - As narrativas que seguem ao longo do texto passaram por um processo transcriação, pois assim como (MEIHY, 2009: 147) compreendemos que o "texto produzido por entrevistas de história oral é passível de tratamento literário", ou seja, a transcriação implica em uma ação criativa e reordenação dos fatores dados na entrevista, não admitindo a invenção de situações mas clareza na exposição. 


\section{Artigos \& Ensaios}

4 - Otávio foi e voltou para São Paulo duas vezes. Em 1976 retornando em 1981, indo pela segunda vez em 1986 e voltando em 1991 para morar em Pão de Açúcar até a presente data.
5 - Maria migrou para São Paulo em 1966, permanecendo durante 25 anos $e$ retornou em 1990. depositária de seus sonhos e esperanças. Neste sentido migrar é apostar no futuro, é resistir ativamente às forças do presente. (SILVA, 2006: 106)

O sr. Otávio[4], filho de agricultor, migrou pela primeira vez aos 16 anos. Assim como os jovens de sua época, também apostou no sonho de um futuro melhor diante da promessa de que, em São Paulo, conseguiria um emprego podendo assim conquistar sua autonomia.

[...] Eu jovem, que todo jovem é sonhador, sonha com uma roupinha melhor né, um sapatinho, um tênis, o básico pelo menos, para ver se consegue namorar pelo menos né. Qual é o jovem que não sonha em arrumar uma namorada e sair pra um baile né, mas como? Com uma sandália Havaina, com uma de uma cor e outra doutra? A minha realidade era essa. Foi isso, aqui em Pão de Açúcar, que me fez migrar pra São Paulo, revoltado, por causa da pobreza tão grande. Eu aprendi fumar apanhando pedaços de cigarro no chão dos outros, porque eu náo podia comprar um cigarro, você veja situação do jovem da minha época, era uma coisa tão angustiante que eu não gosto nem de relembrar sabe. [Otávio, 47 anos. Migrante na década de 70]

Dentre as motivaçóes que resultam na migração de grupos de pequenos proprietários, moradores e rendeiros, estão as favoráveis condiçóes no mercado de trabalho em Sáo Paulo, de forma particular para o jovem que procurava o primeiro emprego. Geralmente a migração era constituída da seguinte forma: o filho mais velho vai e abre caminho para o mais novos. Os parentes que foram primeiro mantêm contato e servem como ligação para os que se determinarem a sair. As famílias gerenciam, facilitando o entendimento de quem vai primeiro e financiando a sua ida. (MENEZES, 1985)

\section{A EXPERIÊNCIA DA METRÓPOLE}

Em São Paulo, o jovem migrante se depara com um duplo aspecto de seus sonhos e esperanças, onde terá que trabalhar de forma particular com sentimentos inversos mas que, a todo momento, misturam-se "o "real": sobreviver e "ideal": conquistar melhores condiçóes de sobrevivência" (MENEZES, 1985: 139). No entanto, a forte determinação de sair para poder construir uma base e em seguida levar os demais que ficaram em Pernambuco sem trabalho, era força encorajadora para enfrentar as dificuldades.

A sra. Maria[5], a primeira de dez filhos de uma família de agricultores, decidiu migrar aos 24 anos. Percebeu que, mesmo trabalhando como costureira, permanecer em Pão de Açúcar não era a melhor escolha, pois enquanto ela tinha uma profissão, seus irmãos não conseguiam trabalho, e as condições de sobrevivência ficavam cada vez mais difíceis. Mesmo sabendo que enfrentar um novo mundo não seria fácil, se determina e é a primeira a migrar, levando depois toda a família.

[...] não foi fácil, não foi fácil, porque deixar a casa dos pais pra ir morar na casa dos outros, foi muito difícil, eu sofri muito. Mas o meu intuito com o sofrimento naquela época, 
meus irmãos não faziam nada aqui, não tinha o que eles fazer, trabalhar. Agricultura já não era mais lá essas coisas, eles viviam sem trabalhar, já tudo rapaz, rapaz e moça, aí eu pensei, eu vou embora pra São Paulo, eu vou arranjar uma casa e vou levar tudo pra Sáo Paulo [...] [Maria, 65 anos. Migrante da Década de 60]

As dificuldades encontradas pelos migrantes ao chegarem a São Paulo eram amenizadas pelas redes sociais formadas pela família, vizinhos e amigos, o que se constituiu, portanto, num importante recurso cultural em todas as etapas do processo migratório: transporte, moradia, trabalho e cuidado na doença. Tal aspecto é analisado em vários artigos e livros, Menezes (1985, 2002, 2010), bem como nos livros de Durhan (1978) e Fontes (2008).

Durhan (1978) enfatiza a importância da família, das redes familiares, vizinhança e de amizade, no processo migratório. Embora não utilize explicitamente a noção de redes sociais, na sua análise está presente uma perspectiva metodológica das redes sociais.[6] A migração é uma estratégia familiar, as formas como se processam o movimento também se situarão no âmbito das relaçóes familiares.

[...] o caráter familiar da migração não se manifesta essencialmente no deslocamento conjunto de famílias inteiras, mas antes na reconstituição total ou parcial de grupos familiares, a partir da migração de segmentos da unidade original. Desse ponto de vista a migração de uma pessoa não é um fato isolado, mas um aspecto de um processo que envolve a movimentação sucessiva de pessoas diferentes e pode-se estender por tempo considerável. (DURHAN, 1978: 130)

A importância das redes sociais aqui é identificada pela ajuda mútua, principalmente na chegada a São Paulo, pois o migrante recém-chegado não dispóe de recursos suficientes para sobrevivência, necessitando, portanto, de acolhimento nas casas dos que já estavam estabelecidos. Tais moradias serviam como ponto de apoio para os que iam e vinham constantemente, não significando, pois uma estrutura física suficiente, até mesmo porque em uma casa com dois cômodos, geralmente situados em curtiços, permaneciam de 6 a 8 pessoas.

[...] morei na casa de um primo meu, depois não deu certo eu ficar na casa deles, aí eu fui morar com outra prima [...] eu morei com os meus primos uns dois ou três anos só. Depois eu fui morar com os meus irmáos que eu mandei chamar eles pra ir embora pra lá... a casa que eu morava era um quarto e cozinha... eram os dois irmãos com mulher e filho pequeno, tudo num quarto e cozinha. Mas logo, logo, cada um foi morar numa casa e eu fiquei só com os meus irmáos solteiros... eram quatro irmáos solteiros [...] [Maria, 65 anos. Migrante da Década de 60]

Os migrantes de Pão de Açúcar, em sua grande maioria, se concentraram em bairros próximos como Vila Alpina e Parque São Lucas, formando, deste modo, 


\section{Artigos \& Ensaios}

7 - O migrante Alfeu foi para São Paulo em 1970, passando 10 anos e retornando em 1980 definitivamente. uma rede de solidariedade cujo intuito era a ajuda mútua diante de qualquer necessidade em qualquer emergência; ajudar os recém-chegados a se sentirem mais ambientados; além de promover reunióes de amigos, festas de casamento, batizado, aniversário etc. Segundo depoimentos dos migrantes, a Vila Alpina e o Parque Sáo Lucas acabaram por se transformar em um dos redutos dos conterrâneos nordestinos na grande São Paulo, chegando por vezes a se confundir com o distrito de Pão de Açúcar, devido a quantidade de pessoas que migraram na mesma época.

As redes sociais também foram de suma importância no que se refere à experiência de trabalho dos migrantes, uma vez que os que já estavam instalados e empregados acabavam por indicar os recém-chegados, além de muitos que já vinham com emprego certo. No entanto, vale ressaltar que, diferentemente de muitos migrantes nordestinos que foram trabalhar nas indústrias metalúrgicas ou automobilísticas de São Paulo, os migrantes de Pão de Açúcar, em grande parte, foram trabalhar nas fábricas de calçados que funcionavam em fundos de quintais e que foram montadas pelos primeiros parentes que decidiram migrar na década de 1950. Ao perceber que a produção de calçados era um negócio promissor, muitos abriram seus próprios negócios.

O sr. Alfeu[7] trabalhou na agricultura com o pai durante sua adolescência. Como os demais entrevistados, por falta de perspectiva de trabalho em seu lugar de origem, decide migrar aos 15 anos de idade. Ao chegar a São Paulo, já tinha o emprego garantido em uma das fábricas de calçados do Parque São Lucas. Passados três anos, abriu sua própria fábrica.

[...] na fábrica a gente foi tendo o conhecimento pra um trabalho melhor, porque a gente foi crescendo dentro da fábrica de calçado, três anos depois a gente começou a fabricar pra nós. Parece mentira, mas quando foi oito meses depois nós compramos um fusca zero, um esforço muito grande... Nós tivemos apenas dois funcionários, era pequeno, era num barraco de madeira que meu pai comprou a casa e nós construímos no quintal de casa. Começamos a fabricar assim, compramos as madeiras, compramos as telhas tudo velha né, emendamos uma na outra eu e Pacaré, nós dois com muito esforço e contente da vida porque nós ia mudar, ia sair do emprego pra fabricar pra gente, só que sofremos no inicio, mas depois deu certo. Quando nós conseguimos pagar a casa, nós começamos a regressar para o Nordeste de novo de um por um, porque náo tava mais dando certo os comércio caíram demais". [Alfeu, 52 anos. Migrante na década de 70]

\section{O retorno para Pernambuco}

Considerando tanto a dinâmica dos espaços em termos socioeconômicos como a dinâmica do ciclo de vida familiar, é importante pensar que a migração de retorno precisa ser pensada na perspectiva dos "movimentos múltiplos". Isto não significa que ela não possa ser estudada como um momento ou uma variedade desta multiplicidade de movimentos.

Embora o migrante tenha uma vida marcada pela permanente mobilidade, há sempre uma localidade que representa a referência de fixação. Os lugares de memória e de pertencimento simbolizam as redes de relaçóes familiares, de amizade e de vizinhança. Em cada ponto da circularidade, o migrante transforma-se. 
Deste modo, a circularidade é constituinte de seu próprio fazer-se, ou seja, de sua construção identitária. (THOMPSON, 1978) Isto é, o migrante constitui-se nas tensôes e ambiguidades de várias categorias e diversos espaços sociais. Nesse sentido, não se trata de verificar as opçóes por ficar ou sair, por uma condição de trabalho ou outra, por um lugar ou outro, mas de compreender como os indivíduos tratam subjetivamente essas possibilidades objetivas de trabalho e vida. A condição de mobilidade não expressa, portanto, desenraizamento, desagregação familiar, mas, antes, uma permanente recomposição e ressignificação de suas redes de relaçóes sociais.

Após a fase do milagre econômico de 1968 a 1973, a economia vivenciou um período de crise e as possibilidades de fixação nas cidades diminuíram em relação às décadas anteriores. Até finais da década de 1960, os movimentos migratórios no Brasil se caracterizavam por áreas de origem e destino mais definidas. A partir da década de 70 , começa a ter maior visibilidade a ocorrência das migraçôes múltiplas, o que redefinia os conceitos de origem e destino. Um importante artigo do demógrafo George Martine (1982) identifica que:

Surgiu na década de 70 um conjunto de informaçóes que dava conta da existência de um substrato importante de trabalhadores que se deslocavam repetidas vezes sobre o espaço a fim de encontrar uma forma de sobrevivência. O comportamento desse substrato nada tem a ver com uma subcultura nômade ou um espírito generalizado de aventura, pois se fundamenta numa busca constante de melhores oportunidades econômicas ou da própria sobrevivência [...]. (MARTINE, 1982: 5)

Neste momento a migração não significa uma ida sem volta, mas no contexto aqui exposto vem marcar o início de várias idas e vindas, que num constante transitar de experiências, demarcam e ampliam os conhecimentos dos migrantes (SILVA e MENEZES, 1999); além de proporcionar uma nova definição diante da comunidade de origem, a qual nunca deixarão de pertencer, e que estará sempre presente no seu cotidiano através das redes sociais de solidariedade, constituídas a partir de relaçôes baseadas no parentesco, amizade e conterraneidade (LYRA, 2003).

Durante as décadas de 1970 e 1980, o sonho de conseguir uma profissão com um salário melhor e benefícios sociais era ainda muito presente. No entanto, o Brasil começa a enfrentar um período de crise, dificultando a permanência dos migrantes em Sáo Paulo, levando-os a novas tentativas de refazer suas vidas na terra natal. Não obtendo sucesso, voltavam para o Sudeste na esperança de encontrar alguma nova oportunidade.

[...] durante o tempo que eu tava em São Paulo eu já vim tentar morar aqui em Pão de Açúcar umas três vezes, mas não dava certo, montei dois bares aqui e também não deu certo [...]. (Alfeu, 52 anos. Migrante na década de 70)

As histórias de sucesso aconteceram ainda nas décadas de 1960 e 1970, antes de São Paulo mergulhar no período de crise econômica. A escassez de trabalho em São Paulo começou a ficar aparente, além do surgimento da produção 


\section{Artigos \& Ensaios}

8 - Palavra popularmente conhecida originada da união de palavra helanca (malha vinda do Sul do País) e a palavra sul = SUL + ANCA = SULANCA. Há também uma significação depreciativa relacionada ao produto, algo como sucata. Tal hipótese tem mais fundamento sendo coerente com o início das confecções que eram cobertas ou roupas feitas pelo povo com pedaços de retalhos, com um acabamento mal feito. Deste modo a "Sulanca" representava uma região extremamente pobre, que buscava sobreviver com meios próprios. Teve seu surgimento no final da década de 1940. de sandálias mais sofisticadas e incrementadas de novas tecnologias, tornando cada vez mais difícil os pequenos e micro-empresários do setor calçadista de Vila Alpina e Parque São Lucas continuarem trabalhando e competindo com um mercado cada vez mais inovador.

O migrante nordestino continua, no entanto, buscando formas de sobreviver e novas condiçóes de vida, mas a lógica do capital que tem por objetivo desenraizar e movimentar o indivíduo rumo às determinaçóes capitalistas, vem afirmando que "o trabalhador tem uma pátria, enquanto que o capital não tem pátria”. (MENEZES, 1985: 150)

Quando decidiram voltar para o Nordeste, esses migrantes continuaram a reproduzir a estratégia de sobrevivência de São Paulo, envolvendo os familiares e amigos próximos na produção de confecçóes de roupas, conhecida na época como "Sulanca”.[8] Deu-se início então, na década de 1980, a uma forte migração de retorno para Pernambuco, continuando por sua vez com as redes de solidariedade, produzindo um movimento inverso, trazendo os parentes que estavam em Sáo Paulo em uma situação desfavorável para trabalharem em Pernambuco. Essa situação "influenciou provavelmente o comportamento do fluxo migratório que afluiu para a região, ampliando o número daqueles que retornaram para fixar residência”. (LYRA, 2003: 72)

[...] aconteceu que veio mais calçado moderno, e a gente não tivemos condição de ir em frente, comprar máquinas modernas, o lucro era pouco não tinha como agir mais. Aí por sorte nossa viemos pra Pernambuco e começamos na Sulanca graças a Deus né. Que até hoje nós estamos na Sulanca, é o pano a confecção, mas quem começou com Sulanca é Sulanca até hoje. [Alfeu, 52 anos. Migrante na década de 70]

\section{SETORES ECONÔMICOS ARTICULANDO OS ESPAÇOS DOS MIGRANTES}

Os primeiros migrantes, na década de 1950, se dirigiram para o Parque São Lucas - SP, começaram a trabalhar com produção de sandálias e atuaram como os elos iniciais de uma extensa rede de parentes, vizinhos, amigos que conectavam o distrito de Páo de Açúcar e o Parque São Lucas.

[...] as primeiras pessoas que migraram foram meus primos, Zé do Galo, Joáo irmão dele e Tota, que era Antonio [...] em 1956 mais ou menos. Eles foram embora, chegaram lá começaram a trabalhar em calçados e deu muito certo. Eles lá fabricavam e fizeram até micro-empresa de calçados, aí foi chamando as pessoas daqui de Páo de Açúcar, pra trabalhar com eles. Foi muita gente trabalhar com eles [...] [Maria, 65 anos. Migrante da Década de 60]

Os que migraram não perderam o contato com suas localidades de origem, mas havia um fluxo intenso de idas e vindas. Visitas de migrantes que retornavam e parentes que viajavam a Sáo Paulo para conhecer, visitar, passar um tempo com os parentes e amigos. Essa mobilidade entre os dois espaços repercute a nível da atividade econômica. Foi assim que a fabricação de calçados foi também implantada no distrito de Pão de Açúcar. Ao visitarem os parentes em São Paulo, trouxeram a idéia de montar uma fábrica de calçados no distrito. 
Havia nesse período, em Pão de Açúcar, uma usina de descaroçamento de algodão conhecida como Taquaritinga Agro-industrial S.A. (Taisa), do grupo Cianê, que sinalizava uma alternativa de trabalho temporário para os moradores locais. No entanto, não conseguia absorver todos os jovens que sonhavam com uma profissão e, assim, não minimizava a ideia da ida para São Paulo em busca das oportunidades de emprego das quais ouviam falar, principalmente ao receberem cartas e presentes dos primeiros parentes que se aventuraram.

Assim, muitos jovens, tanto homem como mulher, iam para São Paulo, levando consigo a imagem da vila de suas infâncias que deixavam para trás, repletos de novas perspectivas, mas com os olhos cheios de lágrimas, levando consigo também a incerteza de um futuro desconhecido.

A década de 1980 é marcada por um forte crescimento regional com a produção de confecçóes. A partir de então, começa a migração de retorno, que se deu tanto pela dificuldade das condiçóes de sobrevivência em Sáo Paulo, como também pelo crescente desenvolvimento da "Sulanca", mudando, por sua vez, os aspectos econômicos na região. Nessa época, a produçáo local se dava em pequenos "fabricos",[9] agrupando toda a família envolvendo todas as pessoas da casa: crianças; jovens; adultos; e ainda parentes ou vizinhos próximos em uma mistura de produção artesanal e industrial.

Nos dias atuais há uma forte migração de pessoas de várias cidades do interior de Pernambuco e de outros estados para a região hoje conhecida como "Pólo de Confecçóes do Agreste". Diante desse contexto o distrito de Páo de Açúcar, desde os primórdios, esteve envolta a um constante processo de migração.[10]

[...] $\mathrm{Na}$ época que eu saí pra lá era uma pobreza muito gran$\mathrm{de}$, as pessoas não tinham nada na vida, só quando chovia e lucrava, e hoje não, a confecção dá muito emprego pra pessoas, só não trabalha que não quer, hoje não se ganha muito dinheiro, mas pra sobrevivência quem tem coragem de trabalhar, arranja a sobrevivência né. É por isso que hoje tem muita diferença daquele tempo [...] cresceu muito, porque muitas pessoas vieram morar em Pão de Açúcar, muita gente de fora que vieram morar em Páo de Açúcar, pelo motivo de Páo de Açúcar oferecer emprego pra essas pessoas. [Maria, 65 anos. Migrante da Década de 60]

[...] O Páo de Açúcar de hoje pra o de antes ele mudou, vamos supor de $50 \%$ pra $100 \%$ né, porque aqui não tinha emprego, aqui não tinha meio de vida nenhum, e graças a Deus agora, tem emprego, tem trabalho pra todo mundo, só não trabalha que não quer mas emprego não falta não, né. Não digo que ganha bem, mas ganha razoável que dá pra ir sobrevivendo, só não trabalha que é preguiçoso. Naquela época Pão de Açúcar não tinha emprego. [Inácia, 57 anos. Migrante na década de 60]

O Pólo de Confecçóes do Agreste é composto pelas cidades de Santa Cruz do Capibaribe, Taquaritinga do Norte, Toritama e Caruaru, dentre outros municípios do Agreste pernambucano. A economia local gira em torno da vasta produção de confecção, que vai desde roupas íntimas, de dormir, de praia/ba-
9 - Pequenas empresas, popularmente conhecidas na região como "fabricos", onde acontece a produção de confecções, geralmente feitas dentro das casas, nos fundos de quintais, $e$ em pequenas garagens.

10 - SILVA, Sandra Roberta Alves Silva. A juventude na "Sulanca": Os desafios da inserção no mundo do trabalho em Taquaritinga do Norte-PE. Campina Grande: 2011. (Dissertação de Mestrado em Ciências Sociais) UFCG/PB. 
nho, esportivas, de lazer, sociais, infantis, profissionais, meias, modeladores, até acessórios têxteis para vestuário, artigos de cama, mesa, banho, artigos de copa/ cozinha, decorativos, produtos industriais e produtos técnicos.

A produção das confecçóes é toda feita no Agreste Setentrional e Central, e se destina às demais regióes do Estado de Pernambuco, além de outros Estados do Norte, Nordeste, e ainda para o Sudeste e o Centro Oeste do país.

\section{Conclusão}

É de estrema relevância, portanto, observar, através das narrativas dos migrantes, as relaçôes com o trabalho e com a família, não deixando de considerar como as lembranças entre passado e presente se apresentam e se colocam como forma de "refazer, reconstruir, repensar, com imagens e idéias de hoje, as experiências do passado”. (BOSI, 1998: 55) Sendo assim, não há possibilidade de falar sobre memória sem remeter-se a história e trajetórias de vida das pessoas, que segundo Bourdieu (1996) é um conjunto de acontecimentos originados de uma história e do relato dessa mesma história.

Segundo Halbwachs (2006), o homem, mesmo em sua memória individual, está sempre ligado ao contexto social no qual se insere, deixando por um instante sua individualidade para fazer parte do todo. Seguindo tal ideia, percebe-se a forte ligação na contextualização histórica, observando a confluência das narrativas, como força dessa consciência coletiva sem deixar de considerar a importância da definição da identidade individual, familiar e de grupo.

Mediante essas trajetórias, as lembranças são subdivididas em marcos da memória havendo pontos de grandes significâncias, que se concentram na vida de trabalho, na agricultura, na ansiedade de conhecer uma nova terra e passar por novas experiências, nos vínculos familiares e de amizade, no forte desejo de retorno e na valorizaçáo do local de origem que vem como ponto culminante dessa trajetória, onde atualmente o dinamismo populacional e econômico da regiáo se apresenta como uma possibilidade de geração de emprego e renda para os moradores locais e também para muitos migrantes de outras regióes do Nordeste.

\section{REFERENCLAS BIBLIOGRÁFICAS}

BOSI. Ecléa (1994). Memória e Sociedade: Lembranças de Velhos. São Paulo: Companhia das Letras.

BOURDIEU, P. “A ilusão biográfica." In: Usos e Abusos da História Oral. Ferreira, M. M. (orgs.) RJ: Ed. Da Fundação Getúlio Vargas, 1996, pp.183-192.

CUNHA, L. H., MENEZES, M. A. "Espaço, Memória e Narrativa”. In: IV Encontro de História Oral do Nordeste. Campina Grande - PB: 2003

DURHAN, E. A Caminho da Cidade: A Vida Rural e a Migração para São Paulo. São Paulo: Perspectiva, 1978.

FONTES, P. Um Nordeste em São Paulo. Trabalhadores Migrantes em São Miguel Paulista (1945-66). Rio de Janeiro: Editora FGV, 2008.

GARCIA JR., A. R. O Sul: Caminho do Roçado - Estratégias de Reprodução Camponesa e Transformação Social. Brasília: Marco Zero/Universidade de Brasília/ CNPq, 1989.

HALBWACHS. M. A Memória Coletiva. São Paulo: Vértice, 2006.

LYRA, M. R. S. B. "Sulanca X Muamba: Rede social que alimenta a migração de retorno”. In: Movimentos Migratórios nas Metrópoles. São Paulo em Perspecti- 
va, v.19, n. 4, p. 144-154, out./dez. , 2005.

LOPES, J.R.B. Desenvolvimento e Mudança Social. 3.ed. São Paulo: Nacional, 1976.

Sociedade Industrial no Brasil. São Paulo: Corpo e Alma do Brasil,

1971.

MARTINE, G. "Populaçôes errantes e mobilidade da reserva de mão-de-obra no Brasil.” In: Comunicação simpósio sobre crescimento demográfico na base da pirâmide social. Campinas, São Paulo: SBPC, 1982.

MAYER, P. "Labour migrancy and the social network". In: HOLLEMAN, J.F. et al. Problems of Transition. Proceedings of the Social Sciences Research Conference 1962. Natal University Press, 1964. p.21-51.

MEIHY, José Carlos Sebe Bom. "Palavras aos Jovens Oralistas. Oralidades". Revista de História Oral. São Paulo: NEHO, ano 2, n.3, p.141-50, 2009.

MENEZES, Marilda Aparecida de. "Juventude, família e migraçôes”. Trabalho apresentado no Simpósio Feminismo, Ação Política e Agroecologia. Recife: FAGES/PPGA/PPGS/ UFPE, 2010.

Migration patterns of Paraíba Peasants. Latin American Perspectives, v. 31, n. 2, Issue 135,p.112-134, mar. 2004.

Redes e Enredos nas Trilhas dos Migrantes. Um Estudo de Familias de Camponeses - Migrantes. Rio de Janeiro: Relume Dumará/JP/UFPB, 2002.

"Da Paraíba prá São Paulo e de São Paulo prá Paraíba [migração, família e reprodução da força-de-trabalho]”. Dissertação de Mestyrado. Campina Grande: Universidade Federal da Paraíba, 1985.

MITCHELL, J.C. Network Analysis. Studies in Human Interaction. Paris: Monographs under the auspices of The Afrika-Studiecentrum,1973.

Social networks. Annual Review of Anthropology, v.3, p.279-299, 1974.

SILVA, M. A. M., MENEZES, M. A. "Migrantes temporários: fim dos narradores. In: NEHO - História”. In: Revista do Núcleo de Estudos em História Oral. No. 1, novembro, 1999.

SILVA, Marcelo Saturnino da. "Entre o bagaço da cana e a doçura do mel. Migraçôes e identidades da juventude rural”. Campina Grande - PB, 2006. (Dissertação de Mestrado em Sociologia). Universidade Federal de Campina Grande.

SILVA, Sandra Roberta Alves Silva. "A juventude na "Sulanca”: Os desafios da inserção no mundo do trabalho em Taquaritinga do Norte - PE". Campina Grande: 2011. (Dissertação de Mestrado em Ciências Sociais) UFCG/PB.

SINGER, P. "Migraçôes internas: consideraçôes teóricas sobre o seu estudo". In: P.Singer. Economia Política da Urbanização. 3.ed. São Paulo: Brasiliense, 1976.

THOMPSON, E. P. A Miséria da Teoria. São Paulo: Brasiliense, 1978.

TRUZZI, O. "Redes em processos migratórios. Tempo Social". Revista de Sociologia da USP, v. 20, n. 1, jun. 2008. 